\title{
Action of sulphate of ammonia on glass
}

\section{Marchand}

To cite this article: M. Marchand (1839) Action of sulphate of ammonia on glass, Philosophical Magazine Series 3, 14:85, 75-76, DOI: 10.1080/14786443908649667

To link to this article: http://dx.doi.org/10.1080/14786443908649667

册 Published online: 01 Jun 2009.

Submit your article to this journal 준

Џll Article views: 2

Q View related articles $₫$ 
by the addition of water. It has a penetrating odour of fruit and of valerian; it is colourless; its specific gravity is 0.894 ; its boiling point is $272^{\circ} \mathrm{Fahr}$; ; it is scarcely soluble in water, but dissolves very readily in alcohol, ather, and oils.

The results of the analysis with oxide of copper were

\begin{tabular}{|c|c|c|}
\hline Hydrogen ........ & $10 \cdot 736$ & $10 \cdot 851$ \\
\hline Carbon & $64 \cdot 723$ & 64.963 \\
\hline Oxygen ......... & $24 \cdot 541$ & $24 \cdot 186$ \\
\hline & $00^{\circ}$ & 100 \\
\hline
\end{tabular}

Which indicate the annexed theoretical composition,

$$
\begin{array}{rrrr}
28 \text { eqs. hydrogen } \ldots \ldots \ldots & 174 \cdot 713 & 10 \cdot 623 \\
14 & \text { carbon } \ldots \ldots \ldots & 1070 \cdot 090 & 65 \cdot 056 \\
4 & \text { oxygen } \ldots \ldots \ldots & 400 \cdot 000 & 24 \cdot 321 \\
& & 1644.803 & 100 .
\end{array}
$$

According to these results, this æther is formed of

1 eq. valerianic acid ..... $10 \mathrm{C}+18 \mathrm{H}+3 \mathrm{O}$

1 ather $\ldots \ldots \ldots \ldots, 4 \mathrm{C}+10 \mathrm{H}+1 \mathrm{O}$

$$
14 \mathrm{C}+28 \mathrm{H}+4 \mathrm{O}
$$

The other properties of this ather are similar to those already known.-Journal de Pharmacie, vol. xxiv. p. 365.

\section{ACTION OF SULPHATE OF AMMONIA ON GLASS. BY \\ M. MARCHAND.}

A mixture of hydrochlorate and nitrate of ammonia attacks glass very strongly, especially when it contains lead; and the same is the case with sulphate of ammonia. This salt, as is well known, if neutral, is converted by the action of heat into an acid salt, giving out ammonia; it may therefore be considered, under these circumstances, as an acid salt. If it be heated in a glass vessel, it begins to fuse at about $284^{\circ}$ Fahr.; up to $536^{\circ}$ it suffers no alteration, but at this temperature it gives out ammonia, and sulphuric acid and sulphite of ammonia sublime, and then it may be observed that the glass is strongly attacked. All the interior surface becomes dull, because combination takes place between the sulphuric acid and the potash of the glass, and temporarily, probably, between the ammonia and the silicic acid. Most commonly the vessel, which is frequently acted upon to the middle of the glass, breaks, and from the fissures there proceeds a sort of saline fixed white mass, difficultly soluble, and which is easily found by the blowpipe to be sulphate of potash. M. Marchand states, that he has also frequently observed that watch glasses containing lead, which he employs to dry substances in vacuo over sulphuric acid, are covered, after a certain time (about two to four weeks) with numerous cracks, and from which he has easily detached small fragments. It was impossible, however, to determine that loss of weight occurred in this case : this phænomenon could not therefore be derived from a disengagement of inclosed air, 
as Bischoff, who has made a similar observation, is inclined to suppose; the same appearances have not been observed on the receivers of the air-pump, nor in any other kind of glass.

Journal de Pharmacie, vol, xxiv. p. 367.

\section{ACONITIC ACID.}

M. Buchner, jun. has investigated the properties of this acid, which was first obtained by M. Peschier of Geneva in 1820 , from the Aconitum napellus and Aconitum paniculatum. M. Reuss, having occasion to prepare a large quantity of the extract of aconite, obtained a considerable portion of a granular dirty white substance, consisting principally of aconite of lime, and this he sent to M. Buchner, who, in order to separate the aconitic acid from it, first washed it repeatedly with water and alcohol, to remove the extractive matter, and then dissolved it in dilute nitric acid. The solution being filtered, the aconitic acid was precipitated by excess of acetate of lead. The precipitate obtained, being well washed and separated by filtration, was diffused through distilled water, and submitted to a current of hydrosulphuric acid until the aconitate of lead was completely decomposed. The sulphuret of lead being separated, the liquor was evaporated with a gentle heat, and the aconitic acid formed a white granular crystalline mass. Some aconites are so rich in. aconite of lime, that nearly as much may be obtained as of pure extract. In order to dry it sufficiently for analysis, the acid was dried in a current of air of the temperature of $248^{\circ}$ Fahr. By combustion with oxide of copper the results obtained were,

$$
\begin{aligned}
& \text { Hydrogen . . . . . . ... } 3 \cdot 44 \quad 3 \cdot 80 \\
& \text { Carbon ......... 41.01 } 41.84 \\
& \text { Oxygen ......... 55.55 } 54.36 \\
& 100^{\circ} \quad 100 \text {. }
\end{aligned}
$$

The composition of the acid as combined with oxide of silver, appeared to be

$$
\begin{aligned}
& \text { Hydrogen } \ldots \ldots \ldots \ldots .2 \cdot 23 \\
& \text { Carbon .......... 48.71 } \\
& \text { Oxygen } \ldots \ldots \ldots \ldots \ldots 449.06 \\
& 100^{\circ}
\end{aligned}
$$

From which it appears that the free acid is composed of

$$
\begin{aligned}
& 4 \text { atoms of hydrogen } . . \ldots .=24.959 \ldots 3.42 \\
& 4 \quad, \quad \text { carbor......... }=305 \cdot 744 \ldots 41 \cdot 84 \\
& \text { 4. , oxygen } \ldots \ldots \ldots=400 \cdot 000 \ldots . .54 \cdot 74 \\
& \overline{\mathrm{C}^{4} \mathrm{H}^{2} \mathrm{O}^{3}+\mathrm{H}^{2} \mathrm{O}}=\overline{730.703} \overline{100}
\end{aligned}
$$

while the combined acid consists of

$$
\begin{aligned}
& 2 \text { atoms of hydrogen } \ldots \ldots=12.479 \ldots 2.02 \\
& 4 \text { " carbon ........ }=305 \cdot 744 \ldots 49 \cdot 45 \\
& 3 \text { " oxygen } \ldots \ldots \ldots=300 \cdot 000 \ldots 48.53 \\
& \overline{\mathrm{C}^{4} \mathrm{H}^{2} \mathrm{O}^{3}} \quad=\quad \overline{618.223} \quad \overline{100^{\circ}}
\end{aligned}
$$

